\title{
Review
}

Acta Cytologica 2015;59:361-369

DOI: $10.1159 / 000441515$
Received: April 13, 2015

Accepted after revision: October 6, 2015

Published online: November 17, 2015

\section{Recommendations on Quality Control and Quality Assurance in Cervical Cytology}

\author{
Margherita Branca ${ }^{a} \quad$ Adhemar Longatto-Filho $^{\text {b-e }}$ \\ a Unit of Cytopathology, National Centre of Epidemiology, Surveillance and Promotion of Health, National Institute \\ of Health (ISS), Rome, Italy; ${ }^{b}$ Laboratory of Medical Investigation (LIM) 14, Faculty of Medicine, University of \\ São Paulo, São Paulo, and 'Molecular Oncology Research Center, Barretos Cancer Hospital, Pio XII Foundation, \\ Barretos, Brazil; ' ${ }^{\text {Life }}$ and Health Sciences Research Institute (ICVS), School of Health Sciences, University of Minho, \\ Braga, and 'ICVS/3B's - PT Government Associate Laboratory, Braga/Guimarães, Portugal
}

\section{Key Words}

Pap test - Cytological screening · Quality control · Quality assurance $\cdot$ Cytopathology

\begin{abstract}
Objective: We aimed to critically evaluate the importance of quality control (QC) and quality assurance (QA) strategies in the routine work of uterine cervix cytology. Study Design: We revised all the main principles of QC and QA that are already being implemented worldwide and then discussed the positive aspects and limitations of these as well as proposing alternatives when pertinent. Results: A literature review was introduced after highlighting the main historical revisions, and then a critical evaluation of the principal innovations in screening programmes was conducted, with recommendations being postulated. Conclusions: Based on the analysed data, QC and QA are two essential arms that support the quality of a screening programme.
\end{abstract}

(c) 2015 S. Karger AG, Basel (c) 2015 S. Karger AG, Base

$0001-5547 / 15 / 0595-0361 \$ 39.50 / 0$

\section{Introduction}

The Papanicolaou (Pap) smear has been an effective tool in cancer prevention in several countries as malignant cells can be observed in cervical samples taken from asymptomatic women. Population-based cervical screening is now practised to a greater or lesser extent in almost all countries of the developed world. Invasive cervical cancer is a rare disease in countries where screening is widely available and adequately conducted, but it remains the most common cause of death in countries without screening programmes, a poor infrastructure and a high prevalence of human papillomavirus (HPV)-induced cancer, and reflect the socio-economic iniquities found for many other diseases [1].

A crucial point prior to the routine implementation of a new screening strategy is the implementation of quality control (QC) programmes regarding the various procedures and steps of the process. Feasibility and cost-effectiveness must also be verified and the indispensable training of all professionals involved as well as monitoring must be organized [2].

The aim of this article is to present basic information on QC and accreditation in the health services, to docu-

\section{KARGER 125}

E-Mail karger@karger.com www.karger.com/acy
Correspondence to: Dr. Margherita Branca

Unit of Cytopathology, National Centre of Epidemiology, Surveillance and Promotion of Health, National Institute of Health (ISS) IT-00161 Rome (Italy)

E-Mail margherita.branca@ fastwebnet.it 
ment the effect of different aspects of QC and quality assurance (QA) for cervical screening as well the research studies that prompted the introduction of reliable and comprehensive guidelines for both internal and external QC in gynaecological cytopathology.

QC had its origins in industry, starting as industrial QC and then expanding, in health care, from clinical chemistry to other laboratories and also into the clinical world, where it took the name QA. The term 'continuous quality improvement' can also be found; this term better clarifies that the purpose of the activity is not about the individualization and the knowledge of errors as much as continuous improvements in timing, performance and achievement of a uniform quality [3]. It would therefore be useful to replace the term QA with the term continuous quality improvement (CQI) for 2 reasons: (1) we cannot guarantee the quality, but only the intention or efforts towards ensuring the quality and (2) CQI includes traditional QC measures in the laboratory but has a wider scope, comprising not only the undertaking of corrective actions (if the laboratory falls below an agreed standard) but also offering continuous improvement in the quality of diagnostic services, a well-coordinated multi-disciplinary professional team and the setting of new and higher standards once original targets have been achieved, in order to further enhance the quality of the service [4].

\section{QA and Accreditation}

The indispensability of QA programmes is recognized by accreditation systems that consider them a priority because one can proceed to the evaluation of the adequacy of resources and the organization of health care institutions. All the major manuals on accreditation (i.e. British, American, Australian and Canadian) refer to the existence of QA programmes, considered essential for ensuring compliance with requirements concerning resources, staff qualifications, administrative management, availability of equipment, etc. Accreditation involves many potential gains for health care organizations and supposedly increases safety and/or improves quality [5].

Organizational structure and QC, in the strict sense, complement each other: if QC makes little sense in the absence of essential structural and organizational requirements, the absence of QC programmes, even in laboratories that are well organized, is definitely a shortcoming. This is extremely important in the cervical screening setting because, currently, the judicious implementation of cytology and HPV testing is mandatory in order to cor- rectly use the potential improvements consequent to the new methodological tools and algorithms [6].

Accreditation is a complex procedure by which a committee of experts, appointed by an independent agency that is autonomous, does not belong to the health care organization and is usually non-governmental, assesses and endorses by certification whether a certain institution or laboratory presents all the programmed requirements (standards) established by a peer group [5]. Accreditation has to be renewed at fixed periods.

\section{Types of Accreditation}

Institutional or operational accreditation is required compliance with minimum organizational requirements in order to be authorised to operate and/or be officially recognized by the national health system. Accreditation is a relevant topic for measuring progress in professional competency and improving standards of laboratory practice [7].

Professional accreditation or quality accreditation or accreditation of excellence is voluntary and a process by which a committee of experts (representing the various health professions), appointed by independent agencies and organizations (also accredited and notified), systematically and periodically evaluates and certifies whether an institution or service satisfies predetermined requirements (standards). The standards are a quality/proficiency indicator accompanied by a reference value or threshold. Professional accreditation standards are usually regarded as optimal and achievable, and implementing accreditation is critical in all settings, including in developing countries $[8,9]$. Accreditation provides a visible commitment by an organization to improve the quality of care of patients, to ensure a safe environment and to continually work to reduce risks to patients and staff [7].

Audit is the inspection and examination of a process or quality system to ensure compliance with requirements. Accreditation in the health field is equivalent to the certification of the system of quality in the industrial world according to the standards of the International Organization for Standardization (ISO). Audit procedures of QA and QC protocols are essential for maintaining standards of quality, and imply a continuous process of education and critical evaluation of all steps related to the quality protocols. This is critical for cytotechnologists and biomedical scientists, in particular, due to the central role that these professionals play in cancer prevention programmes and non-gynaecological cytology [10]. Au- 
dit is a mandatory component in the era of molecular pathology and immunocytochemistry, with the huge amount of diagnostic and prognostic information and the rapid evaluation of equipment and methodologies that demand robust validation studies and continued audit procedures [10].

A variety of international/national accreditation agencies offers certification via external audits for laboratories. These private organizations have to be accredited by the ministries of the different countries. The ISO is a worldwide, non-governmental federation of national standards bodies from more than 140 countries. Its work results in international agreements that are published as a base for setting future universal quality standards [11].

The components of programme evaluation should be carefully planned in order to be coherent and compatible with the objectives, and should include population-based information systems as well as internal and external QC systems. In the absence of population-based information systems, specific surveys can provide some of the necessary information [for a complementary review: 12].

The professional in charge of quality programme administration within the cytopathological laboratory must be selected according to particular skills that involve serious commitment to the rigid protocol for laboratory control, and they must report directly to the Chief Executive Officer of the organization; quality in medicine procedures might be necessarily embraced by a senior leadership that thoroughly evaluates the measurement standards and processes the outcomes [13].

According to ISO 9000, an internationally based certification programme, all the important documentation should be collected in a Quality Manual. QA procedures offer improved guarantees that the procedure protocols will be effectively implemented; QC, on the other hand, only measures outputs. For this reason, it is assumed that ISO 9000 supports good practices for the QA process [14]. In order to achieve the best performance of a laboratory under the ISO 9000 certification, 6 basic elements must be considered: (1) define the quality policy, (2) elaborate the organizational chart of the laboratory, (3) provide job descriptions for all staff members, (4) implement the human resource management policy, including continuous education and a reward system, (5) document all procedures, with special regard for those related to $\mathrm{QC}$, the handling of complaints by laboratory users and the maintenance of equipment and (6) define the organization and its responsibility for quality. Importantly, the Manual should be constantly updated and revised.

\section{Quality, QC and QA}

Every initiative to improve quality and outcomes in health systems starts with an understanding of what is meant by 'quality'. There are many definitions used in relation to health care and health systems as well as in other spheres of professional activity. The following working definitions, used in the context of health services, have different meanings [12]:

Quality. The characteristics of an entity that bear upon its ability to satisfy stated or implied needs.

$Q C$ and $Q A$. These terms have many interpretations because of the multiple definitions of the words 'assurance' and 'control'.

QC: 'Control'. This is when the operational techniques and activities fulfil and verify requirements of quality. It is also ensuring that the technical quality of products, be it slides or test results, fall within pre-established tolerance limits.

$Q A$. This focuses on outcome and involves a global assessment of the process which leads to the outcome. In cytology, the outcome is equated with the care of patients, including all the planned and systematic activities implemented, in order to provide adequate confidence that an entity will fulfil requirements for quality. The term 'quality assurance' is no longer current as it implies that a specific level is 'high quality' and that all efforts should be addressed to identify and correct non-conformities from that level. Today, we realize that quality can, and should be, improved, but that it cannot always be guaranteed because errors are unavoidable.

Continuous Quality Improvement. This term has replaced QA and is currently in use to describe all the activities aimed at measuring, correcting and improving the technical process and outcome of health services: it includes traditional QC in the laboratory, but has a wider scope. The aim of CQI is not to 'check' but to constantly ensure and improve the quality of diagnostic services.

\section{QC and QA in Cervical Cytopathology}

QC in cytopathology is complex because of all the factors that can influence the diagnostic result and it should be a guide for the clinician regarding treatment or therapeutic care. It is therefore a system to prevent and control errors that can occur from the time the cytological examination is requested to its examination and interpretation [15]. 
QC in cervical cytology has the objective of improving the performance of the test in order to eliminate falsenegative and false-positive results [16]. False-negatives are more harmful in a routine examination than falsepositives, since non-diagnosed women may lose out on follow-up and continue to be at risk of developing severe lesions. Nevertheless, failures in the opposite situation are not harmless either, since they may lead to unnecessary surgical procedures that can alter the reproductive and sexual life of women in addition to the obvious psychological impact [17].

Cervical cytology may have problems of sensitivity; over the past 30 years, the false-negative rate in cervical cytodiagnosis (i.e. affected by noise but incorrectly classified as 'not sick' by the test) has been the subject of numerous studies. The estimates for false-negative rates were demonstrated to vary from 2 to $55 \%$ according to van der Graaf and Vooijs [18]. The proportion of falsenegative Pap tests can generate sensitivity indices for conventional smears that vary between 30 and $87 \%$, and specificity of between 86 and 100\% [19]. It must be underlined, however, that increased sensitivity is almost always at the expense of decreased specificity, with unnecessary colposcopy and biopsy, increased anxiety of patients, lost time and inconvenience. This means that it is indispensable to identify and put in action specific and comprehensive methods that can increase both sensitivity and specificity.

In order to establish the goals of intervention, it is necessary to identify the potential errors that can occur in the cytology laboratory, and then judiciously evaluate all steps whereby failures might occur, from the collection of samples to the routine screening and interpretation of microscopic findings [20]. Problems in the examination process also arise, e.g. when neoplastic cells are present but are not recognized, due to attention deficit, insufficient time or lack of experience. On the other hand, problems related to diagnostic interpretation are attributed to the evaluation of these cells as benign, as in the case of an inexperienced professional [21] and inadequate clinical information [22].

\section{The Gold Standard Definition}

A reference or 'gold standard' is a test applied independently to confirm the accuracy of a screening technique. The ultimate development of cervical cancer would be the true gold standard in this case; however, this would require a long-term prospective study involv- ing large numbers of women. Patients screened for cervical cancer are typically managed based on the results of a colposcopic examination, usually with biopsies of cervical tissue when indicated. Therefore, colposcopic or histologic confirmation of the presence of cervical intraepithelial neoplasia or its absence is an acceptable surrogate reference standard. However, precisely which gold standard to use is a controversial matter due to the complex net of cancer development steps and the outcome end points [23].

As a consequence, many studies that evaluate cervical cytology screening tests do not use a reference standard at all. Instead, they compare the proportion of abnormal smears between conventional and new tests, assuming that the additional abnormalities detected by the new test are true-positives and that the test is therefore more sensitive $[24,25]$. However, an increase in the proportion of women with abnormal smears with the new test does not necessarily mean that these women have abnormal histology, as their test results may be false-positive [26]. Additionally, many studies assume that positive and negative test results that are in agreement are truepositives and true-negatives, respectively, whereas in some cases they may actually be in agreement but with false results. If colposcopic or histologic confirmation is not feasible, another acceptable but less valid reference standard is adjudicated by independent panel cytology review [26].

The occurrence of false-negative and unsatisfactory Pap smears supported the primary efforts to develop liquid-based cytology (LBC) methodology and automation-based screening devices [27]. The quality of the evaluation of the performance of these technologies is frequently disputed because they are rarely based on histologically defined outcomes using randomised study designs [28]. In general, the proportion of unsatisfactory samples is remarkably lower in LBC when compared to conventional cytology, and the interpretation of LBC requires less time. However, the cost of an individual LBC test is considerably higher [29], although ancillary molecular testing, such as high-risk HPV testing in the case of atypical squamous cells of undetermined significance (ASC-US), can be performed on the same sample [30]. The economic advantage of LBC due to the reduction of recalls for a new sample depends on the existing rates of inadequate Pap smears, which are highly variable throughout Europe. In addition, LBC can effectively favour the introduction of slide reading automation and the implementation of HPV testing [31]. 


\section{Evidence of the Effect of Different Aspects of QA or QC for Cytological Screening}

Evidence of effectiveness, derived from observational studies, is credible. There are cohort studies involving follow-up of screened women, case-control studies, timetrend studies and ecological- or geographical-correlation studies [12]. There is much convincing evidence based on an International Agency for Research on Cancer multicentre study, in which individual screening histories were linked to cancer registry data [32]. The pooled results provided the basis for recommendations on how often women with negative smears should be rescreened. The study followed the incidence of squamous-cell cervical cancer among women, who, at the age of 35 years, had had 2 negative smears. When considering the impact of screening policy on the target population, as in timetrend or follow-up studies by invitational status, account should be taken of selection bias between participants and non-participants, lead time in subsequent screen-detected cancers [32] and the possibility that cancers may be detected in women with a positive screening test and a negative or non-compliant assessment [33]. Several factors affect the overall quality of cervical cytology, and the achievement of a high level of quality must be implemented in the monitoring of all technical phases [34]. Pap test evaluation comprises a continuum of several pre-analytical and analytical steps including [34]: (1) biological variability, (2) collection of samples (site and sampling method), (3) laboratory procedures, including processing, (4) primary screening (manual or computer-assisted) and (5) interpretation.

\section{Biological Variability}

Failure of exfoliation of malignant cells is a well-documented occurrence [35]. Important variability can occur in exfoliation for positive and negative cervical preparations. Exceptionally, failure of exfoliation is found in some cases of invasive carcinoma of the cervix. In these cases, necrotic tissue can prevent exfoliation, and a high proportion of the smears is in fact unsatisfactory [36, 37]. Failure of exfoliation is more common in post-menopausal women, and false interpretation is also a feature in tissue examination due to sampling errors [38]. The vast majority of false-negative smears and diagnoses of uncertain classification (ASC-US) are credited to the cellular alterations associated with hormone-related changes, immature metaplastic cells and air-drying artefacts, all of which can result in a hyper-estimated interpretation of ASC-US on post-menopausal smears [39]. The detection of a progressive lesion is recognized as much more effective in smears taken from women between 35 and 64 years of age than from women aged 20 years. No additional impact of starting screening at the age of 20 years compared to starting at the age of 25 years has been documented [40]. Women who have never been screened should be prioritized for screening [41].

\section{Collection of Samples}

Technical error in sample-taking depends on the particular aspects of the genital anatomy, sampling methods, errors in identification and/or inadequate training. Careful attention to the step-by-step procedure is required [12]. Sample adequacy is a keystone hallmark for quality in cytology. Sample preparation is critical to allow the optimal performance of cytoscreeners and to avoid reading errors. Conventional smears used to present more slide preparation inadequacies than LBC preparations, and this is an important parameter to take in account to maintain thin-layer distribution of the samples, adequacy in Pap staining, well-preserved glandular representation and low unsatisfactory rates [42].

\section{Laboratory Processing (Staining and Coverslipping)}

It is acknowledged that automation reduces errors of staining and coverslip mounting. Cost could be a limitation to introducing equipment for preparing, staining and mounting coverslips automatically. However, the benefits in terms of quality are recognized [43].

\section{Primary Screening}

Primary screening using cytology smears is a critical area for QC and the training of the professional who does the first reading. The training of the pathologist who signs out the final report is also important. In many laboratories, the volume of work is such that most smears considered 'negative' are seen only by an experienced cytotechnician, although the pathologist checks that the histories and reports are credible and appropriate [42]. This places considerable responsibility on the screener. In addition to recognizing any abnormality, the cytotechnician must be fully aware of all the features which make a smear 'unsatisfactory' or, even more difficult, be able to recognize a sub-optimal sample as artefacts and preparations that are unsatisfactory for a variety of reasons (drying and a paucity of material) can be a recurring problem. Since attempts at interpreting such preparations often lead to diagnostic errors, the preparations should be revised or rejected as unsatisfactory, and a repeat smear requested. A significant number of unsatisfactory Pap smears poten- 
tially have eventual diagnoses of intraepithelial lesions or conditions that are more aggressive. Unsatisfactory smears are more likely to have a history of abnormalities, so peer review of these smears is advisable and prudent [43].

\section{Interpretation}

The recent WHO publication on 'Cytology-based screening methods' has made explicit the trend to interpret the morphology of single cells in terms of disease processes [41]. This can be done with surprising accuracy when the cytopathologist continues to evaluate his observations by correlating the appearance of the cells found in the smear with the cells in the tissue section [39]. Special attention must be paid to abnormalities stemming from inflammation and mild-to-severe intraepithelial lesions [44]. Even when cells from the lesion are seen on the slide and identified by the screener, $100 \%$ accuracy is likely not possible. This happens partly because problems also occur with histological diagnosis and partly because infection or cellular degeneration in the smear can produce effects on cellular morphology that cause errors of interpretation. However, interpretation should always be considered with caution to avoid not only false-negative results but false-positive reports [17, 20,21]. Reading and interpretation of screening are closely associated to the skills of cytoscreeners, and the high quality of their basic theoretical and practical training and continued education. Classification of microscopic findings must follow rigorous criteria for categorising cellular abnormalities in order to avoid errors of interpretation and facilitate comparisons of laboratory performance [45].

\section{Procedures of Quality Improvement}

An extensive revision was recently published dissecting the numerous proposals for quality maintenance in cytology laboratories [12]. Several studies demonstrated the importance of regular activities for verifying pre-analytical and analytical standards $[2,15]$. Internal quality can be addressed with random screening of negative smears, which does not verify rates of false-negative cases. Rapid review or rapid screening of the slides demands time and well-trained staff. Cyto-virological correlation using an HPV test as a reflex test or in combination with cytology screening is a promising tool to optimise screening accuracy. Additionally, guided-computerised screening is an option for enhancing quality as well as the comparison of cytology and histology results [34, 42]. All these elements permit statistical monitoring of laboratory diagnoses, identifying the individual qualities and limitations of the performance of cytotechnologists and cytopathologists. Importantly, the control of workload ratios and the timing of slide-screening are currently proving essential to maintain quality in cytology accuracy $[46,47]$. External audit of the laboratory procedures and diagnoses is also critical to support good cytology practice. Strategies are variable and include the exchange of slides or digital images among laboratories, discussion about selected cases or images, etc. The motivation to introduce and maintain these activities is essential for cytotechnologist and cytopathologist performance.

\section{Personnel Training and Certification}

Training is a critical step for quality in cytology. Trainers must be experienced professionals who stimulate students to observe more than circling coloured areas on a slide, rather targeting cytological abnormalities. The new improvements of molecular and imaging technologies require a multi-disciplinary outlook by the personnel involved with cervical cancer prevention, and cytotechnologists are well qualified for these tasks. Certification is an inherent part of the training process and provides the recognition that the training and continued education were satisfactory [42]. Continuous overseeing of the accuracy and reproducibility of cytological examination (error of the primary screening, from incomplete examination or misinterpretation and error of supervision) is guaranteed by QC programmes which take into account all the possible causes of error $[46,48]$. It should be noted that the smaller the volume of activity (number of Pap tests per year), the more detailed and defined must be the QC programmes that are put in place $[47,49,50]$.

The importance of continuing education for health professionals is crucial. Systematic development in quality is a basic requirement for the introduction of periodic proficiency tests $[16,50]$. QA in cervical cytology was exhaustively discussed at the March 2000 International Consensus Conference on the Fight against Cervical Cancer (Chicago, Ill., USA). This conference was jointly sponsored by the International Academy of Cytology and several national and international organizations; it dealt with QA and error-risk reduction guidelines were addressed as a priority [51]. Since then, measures to improve the quality of the entire screening process have been indicated as being indispensable, and initiatives in this direction have been encouraged. The importance of 
continuous quality improvement processes was emphasised. Although no standards were defined as being applicable to all laboratory settings and nations, the consensus conference provided important views on universal quality procedures. Procedure/policy manuals, workload assessment, hierarchic/peer review, discrepancy analysis, rescreening studies and cytohistological correlation were considered examples of universally applicable quality tools. Strong management commitment and quality organization were stressed as necessary for the implementation of quality measures [51]. The commitment represented by management leadership and the delegation of CQI activities to competent staff, linkage with positive feedback and an interest in auditing and improving the system were clearly indicated. The variability in practice in different parts of the world was also discussed.

In parallel, a transnational programme called CYTOTRAIN (Leonardo da Vinci Programme, 1996-2003) included partners from Italy, France and the UK and was sponsored by the European Commission with the aim of harmonizing training and quality standards in cervical cancer screening throughout Europe [52]. The purpose of the CYTOTRAIN project was to prepare training material for cytopathologists and cytotechnologists engaged in cervical cancer screening, to disseminate products and instruct in their use, as well as to develop a model training programme using the training material. Another intention was to evaluate the various products (booklets, manuals, atlas and CD-ROMS). This training programme was planned for young doctors and other health workers and technicians involved in the microscopic analysis of cervical smears, an integral part of cervical cancer prevention programme in most EU member states. The project was the result of research carried out by groups of experts and professionals, in an effort to respond to specific challenges in their fields [53]. Knowledge and professional skills must, in fact, be regularly updated if we are to meet the new requirements of the economy and labour market, so now, more than ever before, life-long learning is essential for all. The Leonardo da Vinci Programme, which has been the key community instrument in the field of vocational training since 1995, provided concrete responses to these new needs. The results of the projects supported by this programme deserve to be more widely disseminated among the vocational training community, its social partners and policy makers [53].

The need for training, and especially for life-long learning, is becoming increasingly acute in the field of all specialties in medicine [54]. Firstly, relentless developments in the field mean that knowledge must be continu- ally updated and tools are needed upstream, for example training curricula, learning methods, communication systems and mechanisms for exchanging and harmonizing experiences. Secondly, medical expenditure accounts for a growing percentage of the budget of member states, which means that we need to look to less expensive alternatives, such as replacing hospital care with home care [55]. Lastly, the medical and paramedical professions are currently required to have a knowledge of social sciences and public administration, in addition to their traditional scientific and technical skills [56-58].

\section{Concluding Remarks}

In the cytopathology laboratory, quality is directly linked to the microscope, and to avoid false results this should be a paramount activity in quality programmes. Caution should be exercised principally in 2 areas: firstly, in sampling and preparation (both conventional and LBC) and secondly, in the screening and judicious interpretation of any changes. It is also mandatory to systematically monitor the quality of all these procedures and set standards for all of the health professionals involved. Internal quality procedures should be a priority, and an external audit on the QC and QA measures of the laboratory is also required $[59,60]$. Training personnel is fundamental to maintain high-quality skills and experienced and preferentially certified professionals in continuous education programmes. The commitment of top management and quality organization of the laboratory are also not to be neglected.

References

1 Torre LA, Bray F, Siegel RL, Ferlay J, LortetTieulent J, Jemal A: Global cancer statistics, 2012. CA Cancer J Clin 2015;65:87-108.

$\checkmark 2$ DeGroff A, Cheung K, Dawkins-Lyn N, Hall MA, Melillo S, Glover-Kudon R: Identifying promising practices for evaluation: the $\mathrm{Na}$ tional Breast and Cervical Cancer Early Detection Program. Cancer Causes Control 2015;26:767-774.

3 de Jonge V, Sint Nicolaas J, van Leerdam ME, Kuipers EJ: Overview of the quality assurance movement in health care. Best Pract Res Clin Gastroenterol 2011;25:337-347.

-4 Grzybicki DM, Shahangian S, Pollock AM Raab SS: A summary of deliberations on strategic planning for continuous quality improvement in laboratory medicine. Am J Clin Pathol 2009;131:315-320. 
5 Braithwaite J, Westbrook J, Johnston B, Clark S, Brandon M, Banks M, Hughes C, Greenfield D, Pawsey M, Corbett A, Georgiou A, Callen J, Ovretveit J, Pope C, Suñol R, Shaw C, Debono D, Westbrook M, Hinchcliff R, Moldovan M: Strengthening organizational performance through accreditation research - a framework for twelve interrelated studies: the ACCREDIT project study protocol. BMC Res Notes 2011;4:390.

-6 Saraiya M, Irwin KL, Carlin L, Chen X, Jain N, Benard V, Montano DE: Cervical cancer screening and management practices among providers in the National Breast and Cervical Cancer Early Detection Program (NBCCEDP). Cancer 2007;110:1024-1032.

7 Naritoku WY, Alexander CB, Bennett BD, Black-Schaffer WS, Brissette MD, Grimes MM, Hoffman RD, Hunt JL, Iezzoni JC, Johnson R, Kozel J, Mendoza RM, Post MD, Powell SZ, Procop GW, Steinberg JJ, Thorsen LM, Nestler SP: The pathology milestones and the next accreditation system. Arch Pathol Lab Med 2014;138:307-315.

-8 Yao K, McKinney B, Murphy A, Rotz P, Wafula W, Sendagire H, Okui S, Nkengasong JN: Improving quality management systems of laboratories in developing countries: an innovative training approach to accelerate laboratory accreditation. Am J Clin Pathol 2010;134: 401-409.

9 Woodcock S, Fine G, McClure K, Unger B, Rizzo-Price P: The role of standards and training in preparing for accreditation. Am J Clin Pathol 2010;134:388-392.

10 Wilson A: The role of cytotechnologists in quality assurance and audit in non-gynaecological cytology. Cytopathology 2015;26:7578.

11 Klazinga N: Re-engineering trust: the adoption and adaption of four models for external quality assurance of health care services in western European health care systems. Int J Qual Health Care 2000;12:183-189.

12 Branca M, Longatto-Filho A: A Manual for Cervical Cancer Screening and Control. Principles, Practice and New Perspectives. New York, Nova Science Publishers, 2013.

13 Anderson RJ, Amarasingham R, Pickens SS: The quest for quality: perspectives from the safety net. Front Health Serv Manage 2007;23: 15-28.

14 Cullen R, Mason D: Quality assurance in health sciences literature searching: applying the ISO 9000 quality standard. Health Libr Rev 1995;12:173-189.

15 Tworek JA, Henry MR, Blond B, Jones BA: College of American Pathologists Gynecologic Cytopathology Quality Consensus Conference on good laboratory practices in gynecologic cytology: background, rationale, and organization. Arch Pathol Lab Med 2013;137: 158-163.

16 Crothers BA, Booth CN, Darragh TM, Zhao C, Souers RJ, Thomas N, Moriarty AT: Falsepositive Papanicolaou (PAP) test rates in the College of American Pathologists PAP educa- tion and PAP proficiency test programs: evaluation of false-positive responses of highgrade squamous intraepithelial lesion or cancer to a negative reference diagnosis. Arch Pathol Lab Med 2014;138:613-619.

-17 Koss LG: The Papanicolaou test for cervical cancer detection. A triumph and a tragedy. J Am Med Assoc 1989;261:737-743.

18 van der Graaf Y, Vooijs GP: False negative rate in cervical cytology. J Clin Pathol 1987; 40:438-442.

19 Nanda K, McCrory DC, Myers ER, Bastian LA, Hasselblad V, Hickey JD, Matchar DB: Accuracy of the Papanicolaou test in screening for and follow-up of cervical cytologic abnormalities: a systematic review. Ann Intern Med 2000;132:810-819.

20 Frable WJ: Error reduction and risk management in cytopathology. Semin Diagn Pathol 2007;24:77-88.

21 Coleman DV, Poznansky JJ: Review of cervical smears from 76 women with invasive cervical cancer: cytological findings and medicolegal implications. Cytopathology 2006;17: 127-136.

22 Renshaw AA: Rescreening in cervical cytology for quality control. When bad data is worse than no data or what works, what doesn't, and why. Clin Lab Med 2003;23:695-708.

23 Munro A, Leung Y, Spilsbury K, Stewart CJ, Semmens J, Codde J, Williams V, O’Leary P, Steel N, Cohen P: Comparison of cold knife cone biopsy and loop electrosurgical excision procedure in the management of cervical adenocarcinoma in situ: what is the gold standard? Gynecol Oncol 2015;137:258-263.

24 Dijkstra MG, Snijders PJ, Arbyn M, Rijkaart DC, Berkhof J, Meijer CJ: Cervical cancer screening: on the way to a shift from cytology to full molecular screening. Ann Oncol 2014; 25:927-935.

25 Underwood M, Arbyn M, Parry-Smith W, De Bellis-Ayres S, Todd R, Redman CW, Moss EL: Accuracy of colposcopy-directed punch biopsies: a systematic review and meta-analysis. BJOG 2012;119:1293-1301.

26 Scapulatempo C, Fregnani JH, Campacci N, Possati-Resende JC, Longatto-Filho A: The significance of augmented high-grade squamous intraepithelial lesion detection on Pap test examination: partial results from the RODEO Study Team. Acta Cytol 2013;57:489494.

27 Alves VA, Bibbo M, Schmitt FC, Milanezi F, Longatto Filho A: Comparison of manual and automated methods of liquid-based cytology. A morphologic study. Acta Cytol 2004;48: 187-193.

28 Klug SJ, Neis KJ, Harlfinger W, Malter A, König J, Spieth S, Brinkmann-Smetanay F, Kommoss F, Weyer V, Ikenberg H: A randomized trial comparing conventional cytology to liquid-based cytology and computer assistance. Int J Cancer 2013;132:2849-2857.

29 Dalla Palma P, Moresco L, Giorgi Rossi P; Working Group Authors: Health technology assessment of computer-assisted Pap test screening in Italy. Acta Cytol 2013;57:349358.

30 Longatto-Filho A, Naud P, Derchain SF, Roteli-Martins C, Tatti S, Hammes LS, Sarian LO, Eržen M, Branca M, de Matos JC, Gontijo R, Maeda MY, Lima T, Costa S, Syrjänen $S$, Syrjänen K: Performance characteristics of Pap test, VIA, VILI, HR-HPV testing, cervicography, and colposcopy in diagnosis of significant cervical pathology. Virchows Arch 2012;460:577-585.

31 de Bekker-Grob EW, de Kok IM, Bulten J, van Rosmalen J, Vedder JE, Arbyn M, Klinkhamer PJ, Siebers AG, van Ballegooijen M: Liquidbased cervical cytology using ThinPrep technology: weighing the pros and cons in a costeffectiveness analysis. Cancer Causes Control 2012;23:1323-1331.

32 Hakama M: Cervical cancer: risk groups for screening. IARC Sci Publ 1986;76:213-219.

33 Miller AB: Quality assurance in screening strategies. Virus Res 2002;89:295-299.

34 Longatto-Filho A, Schmitt FC: Gynecological cytology: too old to be a pop star but too young to die. Diagn Cytopathol 2007;35:672-673.

35 Basu J, Mikhail MS, Palan PR, Payraudeau $\mathrm{PH}$, Romney SL: Factors influencing the exfoliation of cervicovaginal epithelial cells. Am J Obstet Gynecol 1992;167:1904-1909.

36 Malm P, Balakrishnan BN, Sujathan VK, Kumar R, Bengtsson E: Debris removal in Papsmear images. Comput Methods Programs Biomed 2013;111:128-138.

37 Lai CR, Hsu CY, Li AF: Degenerative necrotic endometrial debris in Papanicolaou smears. The role in the prediction of endometrial pathology. Am J Clin Pathol 2012;137:290-294.

-38 Gilani SM, Mazzara PF: Cytohistologic correlation in premenopausal and postmenopausal women. Acta Cytol 2013;57:575-580.

39 Gupta S, Sodhani P: Reducing 'atypical squamous cells' overdiagnosis on cervicovaginal smears by diligent cytology screening. Diagn Cytopathol 2012;40:764-769.

40 Sasieni P, Adams J, Cuzick J: Benefit of cervical screening at different ages: evidence from the UK audit of screening histories. Br J Cancer 2003;89:88-93.

41 Brouet, N, Eckert LO, Ullrich A, Bloem O: Comprehensive Cervical Cancer Control: A Guide to Essential Practice, ed 2. Geneva, World Health Organisation, 2014.

42 Longatto-Filho A, Schmitt FC: Cytology education in the 21st century: living in the past or crossing the Rubicon? Acta Cytol 2010;54: 654-656.

43 Stein MD, Fregnani JH, Scapulatempo C, Mafra A, Campacci N, Longatto-Filho A; RODEO Study Team from Barretos Cancer Hospital: Performance and reproducibility of gynecologic cytology interpretation using the FocalPoint system: results of the RODEO Study Team. Am J Clin Pathol 2013;140:567-571.

44 Ransdell JS, Davey DD, Zaleski S: Clinicopathologic correlation of the unsatisfactory Papanicolaou smear. Cancer 1997;81:139143. 
45 Nayar R, Wilbur DC: The Pap test and Bethesda 2014. Cancer Cytopathol 2015;123:271281.

46 Utagawa ML, di Loreto C, de Freitas C, Milanezi F, Longatto Filho A, Pereira SM, Maeda MY, Schmitt FC: Pero Vaz de Caminha: an interchange program for quality control between Brazil and Portugal. Acta Cytol 2006; 50:303-308.

47 Renshaw AA, Elsheikh TM: Assessment of manual workload limits in gynecologic cytology: reconciling data from 3 major prospective trials of automated screening devices. Am J Clin Pathol 2013;139:428-433.

48 Alderisio M, Branca M, Erzen M, LongattoFilho A, Derchain S, Tatti S, Vighi S, RoteliMartins C, Leoncini L, Maeda MY, Montis D, Gontijo R, Sarian LO, Syrjänen K: Interlaboratory quality control in gynecologic cytopathology using the novel CONQUISTADOR software. Interobserver reproducibility in the Latin American screening study. Acta Cytol 2007;51:872-881.

49 Renshaw AA: Quality improvement in cytology: where do we go from here? Arch Pathol Lab Med 2011;135:1387-1390.

50 Mody DR, Davey DD, Branca M, et al: Quality assurance and risk reduction guidelines. Acta Cytol 2000;44:496-507.
51 Schneider V, Henry MR, Jimenez-Ayala M, Turnbull LS, Wright TC; International Consensus Conference on the Fight Against Cervical Cancer; IAC Task Force: Cervical cancer screening, screening errors and reporting. Acta Cytol 2001;45:493-498

52 Herbert A, Anic V, Cochand-Priollet B, Dina R, Ehya H, Eide ML, Fabre M, Field A, Kapila K, Kardum-Skelin I, Oliveira MH, Olszewsk W, Onal B, Nasioutziki M, Nayar R, Nielsen K, Shabalova I, Schmitt F, Tötsch M, Wilson A, Vass L, Zeppa P: Training and practice of cytotechnologists: a discussion forum focused on Europe. Cytopathology 2014;25:307-315.

53 Branca M, Morosini PL, Marsan C, Coleman D: Quality assurance and continuous quality improvement in laboratories which undertake cervical screening. Leonardo da Vinci project - CYTOTRAIN 1996-2002, Istituto Superiore di Sanità, Rome, 2002, pp 1-39.

54 Iezzoni JC, Ewton A, Chévez-Barrios P, Moore S, Thorsen LM, Naritoku WY: Selective pathology fellowships: diverse, innovative, and valuable subspecialty training. Arch Pathol Lab Med 2014;138:518-525.
5 Armstrong KA, Semple JL, Coyte PC: Replacing ambulatory surgical follow-up visits with mobile app home monitoring: modeling costeffective scenarios. J Med Internet Res 2014. 16:e213.

56 Kumagai AK, Wear D: 'Making strange': a role for the humanities in medical education. Acad Med 2014;89:973-977.

57 Menchik DA: Decisions about knowledge in medical practice: the effect of temporal features of a task. AJS 2014;120:701-749.

58 Gibson CJ, Dixon BE, Abrams K: Convergent evolution of health information management and health informatics: a perspective on the future of information professionals in health care. Appl Clin Inform 2015;6:163-184.

59 Branca M, Morosini PL, Duca PG, et al: Reliability and accuracy in reporting CIN in 14 laboratories. Developing new indices of diagnostic variability in an interlaboratory study. Acta Cytol 1998;42,1370-1376.

60 Branca M, Morosini P, Severi P, Erzen M, Di Benedetto C, Syrjänen K: New statistical software for intralaboratory and interlaboratory quality control in clinical cytology. Validation in a simulation study on clinical samples. Acta Cytol 2005;49:398-404. 